CIRJE-F-816

The Effects of Medical Factors on Transfer Deficits in Public Assistance in Japan: A Quantile Regression Analysis

Masayoshi Hayashi

University of Tokyo

August 2011

CIRJE Discussion Papers can be downloaded without charge from:

http://www.cirje.e.u-tokyo.ac.jp/research/03research02dp.html

Discussion Papers are a series of manuscripts in their draft form. They are not intended for circulation or distribution except as indicated by the author. For that reason Discussion Papers may not be reproduced or distributed without the written consent of the author. 


\title{
The Effects of Medical Factors on Transfer Deficits in Public Assistance in Japan: A Quantile Regression Analysis*
}

\author{
Masayoshi Hayashi \\ Associate Professor \\ Graduate School of Economics, The University of Tokyo \\ Hongo 7-3-1, Bunkyo-ku, Tokyo 113-0033, Japan \\ E-mail: hayashim <<at>> e.u-tokyo.ac.jp
}

\begin{abstract}
In countries where local governments are heavily involved in financing health care for the indigent, regional disparities in local revenues may adversely affect the access of the poor to medical care. It is thus important to examine how central governments provide funds for such local medical needs. In Japan, local governments finance all medical costs for the poor through their Public Assistance (PA) programs. Using the unique mechanism of the Japanese system of central grants, I construct a measure of "transfer deficit" which shows the portion of the PA expenditures that fails to be secured by the central grants. The distribution of such a measure provides important information to assess the regional equity in financing local programs. The results suggest a compromise on the regional equity in financing medical care for the indigent. Then, I explore the determinants of the deficit measure by performing a quantile regression analysis. Since no effects of potential determinants imply that the central grants well accommodate changes in local needs, finding such effects helps evaluate the performance of the transfer system. The results shows that, among others, the number of PA households and the factors related to mental illness of PA recipients have positive impacts that attenuate toward the top of the conditional quantile of the transfer deficit. I will elaborate on plausible causes of such attenuating responses.
\end{abstract}

Keywords: Public assistance, Transfer deficits, Medical factors, Japan

JEL Classification: H75, H71

\footnotetext{
* This paper is forthcoming in the International Journal of Health Care Finance and Economics. The final version will be available at www.springerlink.com. This study is financially supported by the Grant-in-Aid for Scientific Research (B-20330064) from the Ministry of Education, Science, and Culture of Japan.
} 


\section{Introduction}

Financing health care for the poor remains an important policy issue in many economies. The issue varies across countries according to their institutions and policy contexts (France 2008). In countries where sub-national governments are heavily involved in financing health care for the indigent, one of the important issues is designing the system of central grants. Without central grants, regional disparities in fiscal resources adversely affect individual access to medical care. However, trends toward decentralization and reforms in central grants in many countries have raised concerns for regional equity in health care finance, prompting a growing number of studies to investigate the issue. ${ }^{1}$ While these studies used statistical techniques that utilize sub-national expenditure data, they could have also approached the issue by examining the institutional aspects of central grant systems. However, doing so is not always feasible. $^{2}$

In contrast, such an examination may be feasible in Japan where local governments finance medical care for the indigent as Medical Assistance (MA) provided through a program called Seikatsu Hogo or Public Assistance (PA). ${ }^{3}$ Two types of central grant support local PA programs. The first type, the Central Government Subsidy for Public Assistance (CGS-PA), matches PA benefits at 75\%. The remaining $25 \%$ of the benefits plus the costs of human resources at welfare offices is financed from the general revenue of local governments, which include local taxes. The second type, the Ordinary Local Allocation Tax (OLAT), supports this local burden. The unique mechanism of the OLAT makes it possible, along with the CGSPA, to measure the degree of transfer deficit that shows how the funds secured by the central government for PA programs fall short of the actual amount of PA expenditure. ${ }^{4}$

\footnotetext{
${ }^{1}$ See Sutton and Lock (2000), Gasparini and Ramos (2004), Costa-Font and Rico (2006), Scheffler and Smith (2006), Magnussen et al. (2007), Montero-Granados et al. (2007), Wagstaff and Lindelow (2007), Jiménez-Rubio et al. (2008), Chou and Wang (2009), Costa-Font 2010, and Fang et al. (2010).

2 For example, the Canadian federal government disburses the Canada Health Transfer (CHT) and Equalization payments to its provinces. While the CHT is a categorical grant for provincial health expenditures, Equalization payments are general-purpose and based on provincial fiscal revenues rather than needs. Hence, these institutional aspects make it difficult to measure the extent to which the Canadian system of fiscal transfers helps a specific category of provincial expenditures.

3 In this paper, "Public Assistance" refers to a specific social assistance scheme in Japan.

${ }^{4}$ The term "transfer deficit" was kindly suggested by Professor Pedro P. Barros.
} 
The first purpose of this study is to measure the degree of transfer deficit and examine how such deficit measures are distributed. If the central grant system secures the funds properly, the distribution will be adequate without either large deficits or surpluses. In other words, the distribution of the deficit measure provides important information to assess the regional equity in financing local PA programs. However, studies that have investigated such a measure are almost non-existent. An exception may be a survey by the Japan Association of City Mayors (JACM) (2008) which reports the number of cities in transfer-deficit. However, it does not provide much information. It neither discloses how its respondents calculate their deficits nor shows how the deficits are distributed. I attempt to address these issues in this study.

The second purpose of this study is to explore the determinants of the transfer deficit. Since MA benefits constitute almost half of the PA benefits, it is plausible that the medical needs of PA recipients could affect the deficit measure. However, such medical factors, as well as other relevant factors, would not affect the measure of transfer deficit to the extent that the central transfer system is able to allow for changes in local expenditures brought about by changes in such factors. Hence, finding factors that affect the transfer deficits should help evaluate the performance of the transfer system.

Since this study investigates the determinants of a sort of local expenditure measure, it may be associated with the literature on the determinants of health expenditures by sub-national governments. ${ }^{5}$ However, it differs from the previous studies as follows. First, I do not examine the level of expenditures but rather the proportion of expenditures that the center fails to secure. Second, I do not investigate MA benefits per se, but instead examine the effects of MA on PA, since localities are more concerned with the total outlays of PA programs (JACM 2008). In particular, urban localities like the City of Osaka (2001) claim that MA is a major cause of a significant amount of their transfer deficits. The validity of this claim may be examined by considering the effects of plausible determinants of MA benefits on the transfer deficit of PA programs. In doing so, I in effect examine, albeit indirectly, the

\footnotetext{
5 See Häkkinen and Luoma (1995), Gordon et al. (1997), Di Matteo and Di Matteo (1998), Cantarero (2005), Crivelli et al. (2006), Scheffler and Smith (2006), Costa-Font and Pons-Novell (2007), Moscone et al. (2007), Andersson and Henriksen (2008), Rahman (2008), Mays and Smith (2009), and Costa-Font (2010).
} 
relationships among MA recipients (indigent medical needs), local governments (PA expenditures), and the central government (the degree of PA expenditures secured by the central grants). Third, I utilize quantile regression (QR) to examine the effects of medical needs and other relevant factors. As Moreira and Barros (2010) note, QR is gradually emerging as an alternative to least-squares regression in a wide range of applications. ${ }^{6}$ It estimates different responses of a dependent variable to changes in explanatory variables across the conditional quantiles of the former. The response of the deficit measure depends on how precisely the center estimates local needs so that its transfer system can respond well to the changes in local needs. Since the center estimate the needs with a nationally uniform formula, its precision could vary across localities. In this study, I show how medical needs and other relevant factors affect the deficit measure differently across the conditional quantiles. I also elaborate on plausible causes of such varying responses.

The rest of this paper is organized as follows. In the next section, I describe the PA system and its financing scheme. Then I construct a measure of the fiscal deficit for PA spending, and examine its distribution in fiscal year (FY) 2007. Next, I perform a QR using the deficit measures and discuss the results. Lastly, I present the conclusion.

\section{Institutional backgrounds}

\section{Public Assistance and Medical Assistance}

One of the outstanding features of Public Assistance (PA) in Japan is the prominence of its Medical Assistance (MA) benefits, which constitute almost half of total PA expenditures (Fig. 1). This is because, being the last safety net, PA covers those who are excluded from the upper layers of social programs. Except for PA programs, Japan does not have non-contributory schemes that cover those who are excluded from the systems of social insurance for medical expenses and old-age pensions. ${ }^{7}$ Since these social-insurance schemes are contributory, the injured and sick

\footnotetext{
${ }^{6}$ For different applications of QR, see Koenker and Hallock (2001) and Yu et al. (2003).

${ }^{7}$ Two contributory schemes cover medical expenses in Japan: the Employees' Health Insurance (EHI) for those employed and their families and the National Health Insurance (NHI) for those excluded from the EHI. Once one becomes eligible for PA, he and his household members are excluded from the contributory scheme to which they previously belong. The PA then covers all of their medical expenses through the MA.
} 
without premium payments have to face the full costs of medical services, and the elderly without sufficient contribution records receive either pension benefits below the minimum costs of living or no benefits at all. In such cases, they rely on PA programs.

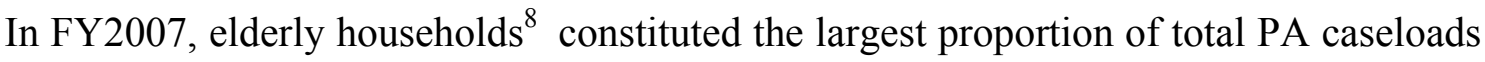
(46.1\%), followed by households headed by the injured and sick $(23.5 \%)$, and those headed by the disabled (13.9\%). Since these three household groups tend to have larger medical demands than others do, it is clear why MA occupies the largest portion of overall PA expenditure.

\section{Fig. 1}

While the Ministry of Health, Labour and Welfare (MHLW) oversees and designs the program, the Public Assistance Law mandates local governments to implement PA programs. PA programs are thus delegated to local governments, and their costs are spent through their budgets. The local administration in Japan consists of two levels of local government: prefectures and municipalities ${ }^{9}$ (i.e., cities, towns, villages, and Tokyo Metropolitan special districts). Meanwhile, the Social Welfare Law requires cities and prefectures to set up welfare offices to implement social assistance and services, including PA programs. Towns and villages are not required to do so, but a small number of them have their own welfare offices. Prefectural welfare offices cover population in towns and villages that do not have their own welfare offices.

Under the Public Assistance Law, the central government sets uniform procedures for local governments to follow in implementing PA programs, described as follows. First, the law warrants unconditional equal treatment. All citizens are equally entitled to claim PA benefits. Only their financial conditions define their eligibility. Second, the law guarantees the minimum costs of living that would enable PA recipients to lead "wholesome and cultured living" as stated in the Constitution. Third, PA benefits would

\footnotetext{
${ }^{8}$ This refers to households that consist of those aged 65 years and above.

${ }^{9}$ Municipalities provide a wide range of services, including education, welfare, public health, fire protection, water, and sewage. Prefectures spatially include municipalities and function as a liaison between municipalities and the central government. They administer services that need the uniform standards within their jurisdictions. They also conduct large investment projects and offer administrative assistance to municipalities. Tokyo contains 23 special districts in addition to cities, towns, and villages. While it functions as a prefecture for cities, towns, and villages, it also provides specific municipal services (e.g., fire protection, water, and sewage) for residents within the special districts.
} 
only supplement the income that an individual can earn with his best efforts. Therefore, PA programs are means-tested and carefully examine an applicant's financial situation. ${ }^{10}$ The amount of PA benefits is then the difference between the minimum costs of living and the actual incomes of recipients.

The MHLW determines the minimum costs of living for households. The formula for calculating the minimum costs uniformly applies across the nation. Localities have no discretion to change them. The minimum costs allocated for each household depend on a variety of variables including the number of household members, their age, gender, and mental and physical conditions. The costs also take into consideration regional price differences.

When PA recipients become injured or sick, the minimum costs include the resulting additional medical costs. It is important to note that one often becomes a PA recipient after becoming seriously sick, injured, and/or disabled, and thus need ongoing medical treatments. The coverage of medical services for PA recipients is identical to that for those enrolled in public health insurance. The MHLW sets the prices for a variety of medical services that apply to all medical treatments that public health insurance subscribers and PA recipients receive. The costs of medical treatments of PA recipients are paid directly to service providers as the MA benefits, which cover all of the costs, including prescribed drugs. In short, medical services are free for PA recipients from their point of use. Furthermore, Japan has no gatekeeping system that rations medical services. PA recipients are free to choose their medical service providers, clinics or hospitals without paying any copayments. This free choice of service provider equally applies to public health insurance subscribers, but they have to pay a $30 \%$ copayment when receiving medical treatments.

\section{Local government and intergovernmental transfers}

The law mandates that localities follow uniform procedures in implementing PA programs. However, these mandates may not always be followed without external funding, especially by localities facing difficulties in financing the mandated

${ }^{10}$ Applicants are required to exhaust their assets before receiving PA benefits. For example, they must sell any land or house they own, unless they live on those properties or if the selling prices are less than the opportunity costs when utilized by the applicants. Household durables may be retained if they are owned by more than $70 \%$ of households in their region. Support from family members or relatives are also required per the Japanese Civil Code. 
expenditures out of their own pockets (i.e., from local taxes). As shown in Fig. 2, for FY2007, the Fiscal Capacity Index (FCI) ${ }^{11}$ varies across cities and only $7 \%$ of cities are self-financing.

\section{Fig. 2}

The center helps localities by providing two types of fiscal transfers: the Central Government Subsidies (CGS) and the Local Allocation Tax (LAT). The CGS is a set of categorical grants disbursed directly from the budgets of line ministries in the center. It includes the CGS for Public Assistance (CGS-PA) that the MHLW disburses to match $75 \%$ of actual PA benefits. Localities bear the remaining $25 \%$ in addition to the staff costs at their welfare offices. The LAT effectively takes care of this local burden, especially in localities with insufficient revenues. The LAT is a general-purpose grant financed out of five national taxes, along with ad-hoc transfers from the central budget.

The LAT consists of two components, the Ordinary LAT (OLAT) and the Special LAT (SLAT). ${ }^{12}$ The OLAT is relevant to PA program. The amount of the OLAT grant disbursed to a locality equals the non-negative difference between the locality's Standard Fiscal Demand (SFD) and Standard Fiscal Revenue (SFR). The SFD estimates the level of local expenditures required to maintain the standard quality of public services, while the SFR estimates local revenues, which consists of a fixed portion of estimated local tax revenues plus some specified transfers. Based on this definition, the SFD does not equal the OLAT grant unless the SFR is zero. In addition, localities whose SFRs exceed their SFDs do not receive OLAT grants.

Nonetheless, the SFD secures the funds for all localities necessary for their expenditures, guarding them against such instances as significant decreases in local taxes. The central government estimates the SFD for multiple categories of local expenditures, including PA. The SFD for PA (SFD-PA) estimates the portion of the total PA costs that the CGS-PA does not cover. Therefore, the combined amount of the SFD-PA and the CGS-PA can be regarded as the funds secured by the central government for localities to implement PA programs, regardless of their fiscal

\footnotetext{
11 The FCI is the three-year average of the ratio of the SFR and the SFD in each locality.

12 The OLAT constitutes $94 \%$ of total disbursements, while the SLAT, which takes care of unexpected fiscal needs not covered by the OLAT, takes the remaining $6 \%$.
} 
capabilities. ${ }^{13}$ Because the SFD-PA is only an estimate, there would be differences between the SFD-PA and the portion of realized local PA costs that the SFD-PA intends to cover, which yields what this study calls transfer deficit.

\section{The measure and distribution of transfer deficit}

\section{Constructing the measure of transfer deficit}

With city data for the Standard Fiscal Demand for Public Assistance (SFD-PA) and the Central Government Subsidy for Public Assistance (CGS-PA), I construct a measure for transfer deficit as

$$
D E F_{i}=\frac{E X P P A_{i}}{C G S P A_{i}+S F D P A_{i}}-1,
$$

where $\operatorname{EXPPA}_{i}, C G S P A_{i}$, and $S F D P A_{i}$ denote respectively Public Assistance (PA) expenditures, the CGS-PA, and the SFD-PA in city $i$. Data for $\operatorname{EXPPA}_{i}$ and $C G S P A_{i}$ were taken from the Ministry of Internal Affairs and Communication (MIC) (2009). Meanwhile, data for $S F D P A_{i}$, while not publicly available, has also been provided by the MIC.

Some items included in what is categorized "PA expenditure" in MIC (2009) and those included in the SFD-PA are not perfectly compatible. The SFD-PA includes costs for all personnel in the welfare offices - not only those in charge of PA programs but also those in charge of other welfare programs. I therefore adjusted the SFD-PA accordingly by reducing its amount, since the SFD-PA assumes that half of welfare office personnel are devoted to PA programs. ${ }^{14}$ There are other items that are included in "PA expenditure" but excluded from either the SFD-PA or the CGS-PA. To allow for the discrepancies, I look into the nine subcategories of "PA expenditure": (a) personnel, (b) supplies and services, (c) maintenance and repairs, (d) assistance benefits, (e) subsidies, (f) ordinary construction works, (g) addition to reserve funds, (h) loans, and

\footnotetext{
${ }^{13}$ Given its definition, transfer deficit could occur even if general local budgets are in surplus.

14 The SFD-PA is a product of the local population, the unit cost, and the adjustment coefficient. The unit cost consists of the per capita cost for the local burden of PA benefits $(25 \%$ of the total benefits plus the personnel costs in welfare offices). Since the SFD-PA assumes that $50 \%$ of the personnel is assigned to the PA program, I calculated the per capita personnel cost as such (¥88.4= $¥ 176.8 / 2$ ) and add this amount to the per capita local burden of PA benefits ( $¥ 481.5$ ) to obtain the unit cost $¥ 5,699$.
} 
(i) transfers to other accounts. Since the costs of the construction and maintenance of shelters for PA recipients are not covered by either the SFD-PA or the CGS-PA but by another item in the SFD, I exclude (c) and (f) from $E X P P A_{i}$ in Equation (1). In addition, (g), (h), and (i) are not specified in either the SFD-PA or the CGS-PA. In the end, I only include the following four subcategories in $E X P P A_{i}$ : personnel, supplies and services, assistance benefits, and subsidies.

Some other discrepancies remain. First, assistance benefits not only include PA benefits but also other benefits that localities provide at their own discretion, which makes the deficit measure (1) overestimate. However, such discretionary benefits have been shown to be negligible (Numao 2009). Second, EXPPA $A_{i}$ includes costs for selfsupport programs that aim to help PA recipients return to labor markets. Half of these costs are covered by the SFD-PA, and the other half are covered by grants other than the CGS-PA. On the other hand, the total costs are dispersed across the four subcategories of the PA expenditure. Since these costs cannot be separated from $E X P P A_{i}$, the resulting deficit measure would be overestimated. Only a small number of cities implement these programs, however, so this discrepancy should not be a cause for concern. ${ }^{15}$ Third, another national grant program separate from the CGS-PA helps localities consolidate their PA implementation, the costs of which are included in PA expenditures. While many localities adopt this program, its shares in total PA expenditures are quite small (Numao 2009), and thus, any bias created by this discrepancy should be minimal.

\section{Distributions of the transfer deficit measure}

Using the definition and the data discussed above, I construct a measure of transfer deficit for local PA spending in FY2007 considering only those cities for which I could make a valid comparison. First, I exclude Tokyo's special districts, since they are not subject to the LAT system. Second, I do not consider towns and villages, as prefectural welfare offices usually cover their populations. Lastly, I also exclude a city (Minami Kyushu) that merged in FY2007. Then, the analysis below covers $83.4 \%$ of the total PA recipients in FY2007.

\section{Fig. 3}

15 There are 28 such municipalities in FY2007. 
Fig. 3 shows the distribution of the measures of transfer deficit. Their value ranges from -0.521 to 0.457 . Out of the 782 cities, $394(50.4 \%)$ have transfer deficits, while the remaining $49.6 \%$ have surpluses. In addition, $5.8 \%$ of the cities had more than $20 \%$ surplus $(D E F<-0.2)$ and $17.2 \%$ had more than $10 \%$ surplus $(D E F<-0.1)$. On the other hand, $4.6 \%$ of the cities had more than $10 \%$ deficit $(D E F>0.1)$ and $0.4 \%$ had more than $20 \%$ deficit $(D E F>0.2)$. The number of cities in deficit exceeded those in surplus, with a positive median of $0.012 .{ }^{16}$ Meanwhile, results from the survey by the Japan Association of City Mayors (JACM) (2008) show that the SFD-PA underestimated the local costs for PA programs in $354(52.4 \%)$ of the 676 cities that responded to the survey. Recall that, while its bias is minimal, the measure (1) tends to overestimate the transfer deficit. Results from our sample show fewer cities (50.4\%) in deficit than those from the JACM survey (52.4\%). This may be a consequence of sample selection, as cities having transfer surpluses may not have wanted to answer the survey.

As Fig. 3 implies, a tighter (more equitable) distribution of DEF around zero could be attained by taking secured funds away from those located on the left-hand side of $D E F=0$ and transferring them to those on the right-hand side. However, the surpluses and the deficits would not necessarily balance in aggregate, since the measures are expressed in ratios. The total PA expenditures in excess of the combined CGS-PA and SFD-PA over the 782 cities amounted to -111 billion yen in FY2007, indicating that there was a deficit in aggregate. Since the total amount of PA expenditures of the 782 cities was 2,328 billion yen, the aggregate deficit amounted to $4.78 \%$ of the total PA expenditures.

\footnotetext{
${ }^{16}$ I checked the normality of the deficiency distribution. A Q-Q plot, which will be provided on request, implies that the quantiles of the distribution of the deficit measures against those of a normally distributed variable are different. The distribution is skewed to the left with the third moment of -0.937 . I also performed a set of normality tests. The skewness and kurtosis test by D'Agostino et al. (1990) and Royston (1991) rejects the null hypothesis of the normality with virtually zero $P$ values. The null hypothesis is also rejected by two additional types of normality test — that of Shapiro and Wilk (1965) and that of Shapiro and Francia (1972) - again with virtually zero $P$ values in both cases.
} 


\section{Determinants of transfer deficits}

\section{Quantile regression}

This section illustrates the quantile regression $(\mathrm{QR})$ analysis performed to explore the possible causes of variation in the measure of transfer deficit $\left(D E F_{i}\right)$. The conditional quantile function of the continuously distributed random variable $D E F_{i}$ is defined as

$$
Q_{\tau}\left(D E F_{i} \mid \boldsymbol{x}_{i}\right)=F^{-1}\left(\tau \mid \boldsymbol{x}_{i}\right)
$$

where $F\left(d \mid x_{i}\right)$ is a cumulative distribution function of $D E F_{i}$ at $d$, given a vector of conditioning variables $\boldsymbol{x}_{i}$. A specific form of $F()$ is not assumed. On the other hand, a linear regression model is specified as

$$
D E F_{i}=\boldsymbol{x}_{i}^{\prime} \boldsymbol{\beta}_{\tau}+u_{i}
$$

where $\boldsymbol{\beta}_{\tau}$ is a vector of coefficients that may vary across different quantiles indexed by $\tau$, and $u_{i}$ is the corresponding error term. The QR estimator for $\boldsymbol{\beta}_{\tau}$, then, would be given as a sample analogue of

$$
\hat{\boldsymbol{\beta}}_{\tau} \equiv \underset{\boldsymbol{b}}{\arg \min } E\left\{\rho_{\tau}\left(D E F_{i}-\boldsymbol{x}_{i}^{\prime} \boldsymbol{b}\right)\right\}
$$

where $\rho_{\tau}$ is the check function defined as

$$
\rho_{\tau} \equiv 1\left\{D E F_{i}-\boldsymbol{x}_{i}^{\prime} \boldsymbol{b}>0\right\} \cdot \tau\left|D E F_{i}-\boldsymbol{x}_{i}^{\prime} \boldsymbol{b}\right|+1\left\{D E F_{i}-\boldsymbol{x}_{i}^{\prime} \boldsymbol{b} \leq 0\right\} \cdot(1-\tau)\left|D E F_{i}-\boldsymbol{x}_{i}^{\prime} \boldsymbol{b}\right| .
$$

This asymmetric weighting scheme results in a minimand that selects conditional quantiles. The variance-covariance matrix estimator (VCME) for $\hat{\beta}_{\tau}$ is derived as shown by Buchinsky (1998). Since the evaluation of the VCME for QR is somewhat complicated, the literature recommends bootstrapped standard errors for $\boldsymbol{\beta}_{\tau}$ for inference, which I follow in the following section.

\section{Choice of explanatory variables}

Ideally, a theoretical framework should specify the explanatory variables to be included in a regression model. However, as Gerdtham and Jönsson $(2000,19)$ have pointed out, the literature on "the determinants of aggregate health expenditure" is marred by a "weak theoretical base" and provides "little guidance as to the possible explanatory variables and the causal mechanism involved." This critique also applies to 
similar studies on the determinants of health expenditures by sub-national governments $^{17}$ and, thus, to the current study as well. In studies such as this, the choice of explanatory variables is usually based on those from previous similar studies (Andersson and Henriksen 2008).

While literature on the determinants might have provided us with some guidance in variable selection, there are no studies that exactly parallel the current one. Therefore, in the regression analysis, I simply use the variables of direct interest, along with other plausible controls, to check how these factors account for variations in the transfer deficits. Fortunately, the choice of the explanatory variables is clear: since Medical Assistance (MA) benefits comprise almost half of Public Assistance (PA) expenditures, this study is interested in examining the effects of medical needs of PA recipients on the transfer deficits.

I therefore include the variables that reflect the medical needs of PA recipients. These variables come from a set of unpublished data on local PA programs, compiled by the MHLW. They include (a) the number of households that receives PA (hereafter, "PA households"); (b) five categories of PA households, defined by types of household compositions or heads (i.e., elderly, single-mother, disabled, injured or sick, and others); (c) the number of household members in PA households (hereafter, "PA recipients"); (d) the number of PA recipients who receive MA (hereafter, "MA recipients"); and (e) the number of MA recipients in four categories (mentally ill MA inpatients, other MA inpatients, mentally ill MA outpatients, and other MA outpatients). These data are valid as of October 1, 2007, and are aggregated at the municipal level.

I utilize these data to construct the following four share variables that directly represent the medical needs of PA recipients: (i) the share of MA recipients among PA recipients, (ii) the share of inpatients among MA recipients, (iii) the share of the mentally ill among MA recipients, and (iv) the share of inpatients among mentally ill MA recipients. I also include the following three shares among PA households: (v) elderly households, (vi) households headed by the sick or the injured, and (vii)

\footnotetext{
17 Häkkinen and Luoma (1995) refer to the median voter model as a theoretical framework. However, Gerdtham and Jönsson (2000), in the words of A. J. Culyer, point out that since the events to be explained are highly stylized and the theory highly selective, the resultant explanatory variables resulting from this framework are unavoidably crude.
} 
households headed by the disabled. Table 1 lists the variables concerning the medical needs of the PA recipients mentioned above, along with their definitions. ${ }^{18}$

\section{Table 1}

In addition to the medical-needs variables described, I also utilize the MHLW data to construct the following control variables. To allow for the size of PA caseload, I consider (viii) the natural logarithm of the number of PA households. I also add (ix) the natural logarithm of the average PA household size. Lastly, I add (x) the natural logarithm of the population and (xi) that of the surface area of each municipality, both obtained from MIC (2009). These two covariates, together, would control for a variety of factors such as city size, population density, and other factors that would be difficult to specify. ${ }^{19}$

Although there are no studies that are directly comparable to the current one, those on health expenditures by sub-national governments are somewhat related. I therefore refer to them when determining the explanatory variables of this study. While the details of the determinants vary depending on the specifics of the study, two variables have been frequently used: elderly population and per capita income (Häkkinen and Luoma 1995; Crivelli et al. 2006; Di Matteo and Di Matteo 1998; Cantarero 2005, Costa-Font and Rico 2006; Moscone et al. 2007; Rahman 2008; Mays and Smith 2009; Costa-Font 2010). However, I do not include these variables for two reasons. First, I have already controlled for the elderly population by including the share of the elderly households among PA households. Second, the PA benefits effectively equalize the income levels of PA households at the minimum costs of living, since the benefits equal the differences between the minimum costs and actual income of the recipients.

\footnotetext{
${ }^{18}$ We could have categorized these variables into those which public sector can control and those it cannot. For example, health promotion programs could control for the shares of (i) MA recipients among PA recipients; (ii) inpatients among MA recipients; (iii) the mentally ill among MA recipients; (iv) inpatients among mentally ill MA recipients; and possibly (vi) PA households headed by the injured or sick. However, the effects of such health promotion policies may only be realized on a medium- or long-term basis.

${ }^{19}$ Other plausible variables to be included are political variables. For example, Leigh (2008) showed that welfare caseload is approximately $1-2 \%$ higher under a Democratic governor in the US, implying that partisan differences matter. However, partisanship is often unexpressed in Japanese elections at the municipal level and, as such, would be difficult to assign formally to city mayors or city councilors.
} 


\section{Some diagnoses and caveats}

I utilize a cross section of city data for 2007. One might wonder if the relative positions of the cities under consideration change significantly owing to year-to-year fluctuations. Since I do not have comparable data for another year, I cannot examine this issue for all the variables used in the analysis. However, the MIC has provided data that I can utilize to calculate the measure of transfer deficit for FY2006. I then repeat the procedure to obtain the measures and compare them against those for FY2007. ${ }^{20}$ Fig. 4 illustrates this comparison by measuring the FY2006 values vertically and the FY2007 values horizontally, and plotting their values along with a linear fitted line. The figure shows that while there are several observations that veered off the linear line, the relative positions of the cities are rather stable. In particular, it is notable that the relative positions of the cities with extreme values (i.e., those with the largest and smallest transfer deficit measures) have not changed during the period.

\section{Fig. 4}

Table 2 lists the descriptive statistics for the variables used in the regression analysis. It also includes the coefficients for the variance inflation factor (VIF) for each of the eleven explanatory variables. As a rule of thumb, a VIF of more than 10 indicates the existence of excessive multicollinearity (O'Brien 2007). In addition, the mean value of VIFs for all explanatory variables should not be considerably larger than unity when multicollinearity is not severe. ${ }^{21}$ The table shows that the highest VIF is 4.1 , for the $\log$ of PA households, which is well below $10 .^{22}$ In addition, the mean value of the VIFs over the eleven variables is 2.4 , which is not substantially larger than unity. Based on the above, I conclude that the effects of multicollinearity are minor.

\section{Table 2}

In addition, some of the explanatory variables might be endogenous. Localities carry out means tests to assess the needs of PA applicants and certify their eligibility. When their transfer deficits are large, they may reject more PA applicants than they would otherwise. If this were the case, there would be a reverse causation from the

\footnotetext{
${ }^{20}$ I excluded cities that merged in FY2006 and FY2007, leaving 774 cities in Fig. 4.

${ }^{21}$ See STATA Corporation (2009). Also, see O'Brien (2007) for the use of VIFs.

${ }^{22}$ O'Brien (2007) cites a study that argues that the VIF should be less than 4. Since this highest VIF exceeds 4 only by 0.1 , this should not be a cause for concern.
} 
dependent variable. However, there are two arguments against this concern. First, this reverse causation would not be severe as this study focuses on those recipients who have more medical needs, such as the elderly, the disabled, and the injured or sick. In fact, elderly applicants receive PA benefits almost automatically if their pensions are less than the minimum costs of living. A similar argument applies to the disabled and the injured or sick. Second, localities are supposed to follow the uniform national procedures when implementing PA programs. The Ministry of Health, Labour and Welfare (MHLW) monitors local implementation through a hierarchy of audits and supervisory measures. For instance, there are supervisors who oversee the daily work of caseworkers in local welfare offices. In addition, the MHLW commissions prefectures to conduct audits of cities within their jurisdictions. The MHLW also directly conducts special audits on prefectures and large cities. Finally, the central government temporarily transfers their officials from their office to hold managerial positions in welfare-related sections in local governments. Because of these thorough audit measures, localities are likely to follow the nationally uniform procedures and thus, reverse causation should not be a serious problem.

Although this line of argument leads to a claim that the simultaneity is not a major concern, there may be yet another source of endogeneity. There may be an unobserved heterogeneity that correlates with at least one of the explanatory variables. While I was able to obtain data for the dependent variable for another year (FY2006) as in Fig. 4, I could not obtain analogous data for the explanatory variables so that there is no panel of city data to "difference out" the unobserved heterogeneity. I may instead employ the instrument variable estimator for this cross section of city data to address this endogeneity. However, it would be hard to find explanatory variables that correlate with the unobserved heterogeneity, let alone to find their instruments. Therefore, I have no choice but to assume that the eleven regressors are good enough to reduce the bias to an acceptable level.

\section{Estimation results}

Table 2 lists the results for the quantile regressions at the $0.15,0.25,0.50,0.75$, and 0.85 quantiles. As a benchmark, it also shows the ordinary least squares (OLS) estimates in the first column. Note that the OLS results are different from the quantile 
regression results, suggesting that the model is not that of location shift. To confirm this, I tested the null hypothesis of constant coefficients at the five quantiles, and reported the results in the last column. In addition, to better illustrate how coefficients vary across quantiles, I plotted the coefficient estimates at eighteen quantiles $(0.05$, $0.10,0.15, \ldots, 0.90$, and 0.95 quantiles) in eleven panels, along with their 90 and $95 \%$ confidence intervals, as shown in Fig. 5.

\section{Table 2 and Fig. 5}

Before discussing the specifics of the estimation results, I elaborate on the interpretation of the coefficient for each explanatory variable. If the coefficient for an explanatory variable is zero, a change in that explanatory variable will not affect the dependent variable, i.e., the deficit measure (1). This happens if the Standard Fiscal Demand for Public Assistance (SFD-PA) is able to accommodate change in the local burden of PA programs brought about by a change in the needs, as expressed by the explanatory variable. On the other hand, if the coefficient on the explanatory variable positive (negative), it means the SFD-PA underestimated (overestimated) such a change, leading to an increase (a decrease) in the deficit measure. What is important here is how the central government estimates the SFD-PA, since the other central grant, the Central Government Subsidy for Public Assistance (CGS-PA), simply matches $75 \%$ of the actual PA benefit payments. A summary of the effects of each of the eleven explanatory variables, categorized into three groups, is shown below.

\section{Characteristics of MA recipients}

First, the share of Medical Assistance (MA) recipients among PA recipients has negative but statistically insignificant impact except at the .25 quantile. The OLS estimate is also statistically insignificant. Panel (i) in Fig. 5 illustrates these results. It may be safe to argue that the effect of the share of MA does not exist, suggesting that the medical needs of the PA recipients are well accounted for in the SFD-PA, although it is important to note that I obtain this result by controlling for the variables that also characterize MA recipients. Second, the share of inpatients among MA recipients has a negative effect at every quantile, although it is statistically significant only at lower quantiles. This is supported by the rejection of the constant coefficient. Meanwhile, the OLS estimate is negative and statistically significant. These results suggest that the LAT 
system, ceteris paribus, is likely to assign a larger amount of SFD-PA to those cities with higher inpatient MA shares. Third, the share of mentally ill among MA recipients has a positive and statistically significant effect except at the highest quantiles. This effect attenuates toward the top of the quantiles, which is supported by the rejection of the constant coefficient. Lastly, the share of mentally ill inpatients among MA inpatients also has a positive and statistically significant effect at every quantile, except those at the very top and bottom. Although the constant coefficient is not rejected, the share's effect attenuates toward the top of the quantiles, as illustrated in Panel (iv) of Fig. 5.

\section{Characteristics of PA households}

First, the share of elderly PA households has a positive and significant (at the .10 level) impact at the lower quantiles except those at the bottom, but has a negative and insignificant effect at higher quantiles. The OLS estimate is insignificant and the constant coefficient rejected. These results, as illustrated in Panel (v) of Fig. 5, implies that the effect attenuates toward the top of the quantiles. Second, the share of PA households headed by the injured or sick has a positive and significant impact at lower quantiles. The OLS estimate is also positive and statistically significant and the constant coefficient not rejected. The effect also attenuates toward the top of the quantiles, as illustrated in Panel (vi) of Fig. 5. Lastly, the share of PA households headed by the disabled has no statistically significant effect at any quantile. The OLS estimate is not significant either, and the constant coefficient not rejected. As with the MA share, these results suggest that the SFD-PA is able to accommodate the medical needs of disabled households. This is understandable since the probability of being disabled is stable over time and thus the needs of these disabled households would be predictable in the calculation of the SFD-PA.

\section{Other controls}

First, the number of PA households has a conspicuously positive and statistically significant impact at every quantile. This impact attenuates toward the top of the quantiles, as illustrated in Panel (viii) of Fig. 5. The constant coefficient is also rejected. Caseload size plays an important role in this case as it reflects the total volume of medical needs of the indigent. In addition, since the variables discussed so far may not exhaust all the needs of PA recipients, it is understandable that PA caseload has a 
conspicuous effect. Second, the average PA household size has a significant and negative impact at higher quantiles. This negative impact is expected, given that the minimum costs of living are calculated on a per-household basis, and as such, per-head costs decrease as household size increases. In addition, per-recipient costs for caseworkers also decrease as household members increase. This result, however, also indicates that the SFD-PA does not accommodate changes in the PA costs brought by different family sizes. It is also interesting to note that this negative effect becomes more noticeable toward the top of the quantiles, which is the inverse of cases where the positive effect decreases toward the top of the quantiles. Lastly, both population and surface area have negative and statistically significant impacts at every quantile. These results may reflect the influence of unobserved factors that correlate with either population, surface area, or both. Although no clear explanation is evident, these results imply that the calculation of the SFD-PA tends to give advantages to more populated and/or spacious localities.

\section{Discussions and interpretations}

Based on the results above, three points emerge that are worth mentioning. First, the SFD-PA allows well for only two factors, the share of MA recipients and the share of disabled PA households, as implied by their insignificant effects on the transfer deficit. However, the majority of the variables considered here more or less affect the transfer deficit. This should not be surprising given the distribution of the deficits as illustrated in Fig. 3. If these factors had been well accounted for by the SFD-PA, the distribution should have had a smaller spread than that it actually had.

Second, among the four variables that directly represent the medical needs of PA recipients, the two psychiatric-related variables (the share of mentally ill patients among MA recipients and the share of mentally ill inpatients among MA patients) have conspicuous impacts. The number of mentally ill PA recipients had increased in a rapidly in the past several years, from 131,592 in 1996 to 204,600 in 2005 - a 55\% increase (MHLW 2008). In addition, mentally ill inpatients on average stay at hospitals for 291 days in 2008, and the 25\% of them stays for more than 10 years (MHLW 2010). This is by far the lengthiest among OECD countries, followed by Korea whose average was 89.8 days in 2005 (Woojin et al. 2010). Since 20\% of the mentally ill inpatients 
receive MA benefits (Suzuki 2008), the long stays at hospitals imply a large burden for localities. The estimation results imply that the SFD-PA may have failed to accommodate for the increasing number of mentally ill PA recipients as well as the costs of their hospital stays. In fact, a close examination of the SFD-PA reveals that its formula is unlikely to capture changes in the mental health care costs. ${ }^{23}$

Third, in cases where the impacts of the determinants are positive and statistically significant, they tend to attenuate toward the top of the quantiles. In particular, this observation applies to the effects of the two psychiatric-related variables, the share of elderly households, the share of households headed by the injured or sick, and the log of PA households. Assuming that localities follow the uniform procedures, varying responses of the deficit measure should originate from varying responses of the SFD-PA to changes in the PA needs across localities. The attenuating impacts thus imply that the SFD-PA is better able to handle such changes in localities at upper conditional quantiles. Since errors are inevitable in estimating the SFD, the central government has established an institutional procedure through which it addresses issues brought about by localities regarding the SFD estimation. If the transfer deficits increase, localities are likely to finance a larger portion of the deficits out of their own pocket. Therefore, localities with larger transfer deficits are more likely to request changes in their SFD calculations. Indeed, since this system started in 2000, these localities have been requesting the changes almost every year. In response to their requests, the central government has changed the formula for estimating the SFD-PA in 2003, 2004, and $2005 .^{24}$ Therefore, it is possible to infer that it revised the SFD-PA formula in favor of localities with higher transfer deficits, resulting in the positive impacts that attenuate toward the top of the quantiles. ${ }^{25}$

\footnotetext{
${ }^{23}$ For the details on the formula for the SFD-PA, see Konishi (2009).

24 The documents containing the details of the scheme as well as the lists of local requests are available from the MIC website (http://www.soumu.go.jp/main_sosiki/c-zaisei/kouhu.html).

${ }_{25}$ This implies that an increase in the value of those variables would make the conditional distribution of the deficit measure tighter, while at the same time increasing its conditional average as implied by the OLS estimates.
} 


\section{Concluding remarks}

This study aimed to measure the degree and distribution of transfer deficit in Japan by exploiting its unique system of central grants. It was shown that $50.4 \%$ of cities in our sample were in deficit and the rest were in surplus in FY2007. The spread of the measure was rather wide, implying a compromise in the horizontal equity in the financing of PA programs. This suggests that policy makers at the center would attain a tighter, more equitable distribution of the transfer deficit by taking secured funds away from localities on the left-hand side of the deficit measure and transferring them to localities on the right-hand side.

This study has also conducted a QR analysis to examine the determinants of the transfer deficit. If the coefficient on an explanatory variable is zero, it means that the SFD-PA perfectly accommodates the changes in PA expenditures caused by changes in the explanatory variable. The analysis has shown that the SFD-PA was only able to do so for two factors - the share of MA recipients and that of disabled PA households. The analysis has also shown that two psychiatric-related variables had conspicuous positive impacts on the deficit measure. An implication of this finding is that the center, when estimating the SFD-PA, should pay more attention to cost differences in psychiatric care across localities, as well as to other factors that affect the transfer deficits. However, reforming the system of central grants may not be so straightforward. The QR analysis has further shown that the positive impacts tended to attenuate toward the top of the quantiles. This then should imply that the SFD-PA is better able to handle changes in PA needs in localities with larger transfer deficits, which may be a result of the feedback system for the SFD estimation formula.

There may be three possible alternatives for reforming the grant system. The first alternative involves significantly changing the SFD-PA estimation so that it better accommodates local needs. The MIC currently calculates the SFD-PA as a product of the local population, the per capita cost, and the adjustment coefficient. It rigidly sticks to this three-variable formula, and adjusts it only through changes in the adjustment coefficient, which could possibly constrain the approximation of the SFD-PA to the actual local burden of PA programs. The second alternative is to make the CGS-PA cover all costs pertaining to PA program, instead of just matching $75 \%$ of PA benefits. A downside of this, however, is that if the center fully matches the costs of PA 
programs, there might be adverse incentive effects for localities implementing the programs. The third alternative involves the center assuming complete responsibility for the implementation of PA through its local offices. The central government, through the MHLW, has been directly administering the system of unemployment benefits and employment search assistance through its local offices. Therefore, it should not be too difficult to integrate PA programs into the functions of the local offices. In addition, the direct implementation of social assistance by a central government is in place among some OECD countries such as Australia and the UK.

This study, as with others, has limitations. First, the deficit measure (1) could possibly overestimate, although the bias would be minimal. Second, the sample may not describe the entire picture of PA programs as it has excluded Tokyo's 23 special districts, towns, and villages, although it covers a significant portion $(83 \%)$ of the total PA households. Third, there may be an endogeneity problem caused by unobserved heterogeneity from the use of cross-sectional data. If the panel version of the data were available, it would be possible to check for the robustness of the results by performing a panel analogue of QR (e.g., Gamper-Rabindran et al. 2010). Lastly, and possibly most importantly, this study has only focused on the issue of equity. If there are tradeoffs between equity and efficiency, local revenues totally secured by the center might give localities incentives that could adversely affect their implementation of PA programs. These adverse effects are another important topic that needs to be examined in future research.

\section{References}

Andersson, L., \& Henriksen, A. (2008). What determines local expenditures on mental health care in Sweden really? Working Paper Series No.8-2008. Swedish Business School at Örebro University.

Buchinsky, M. (1998). Recent advances in quantile regression models: A practical guideline for empirical research. Journal of Human Resources, 33(1), 88-126.

Cantarero, D. (2005). Decentralization and health care expenditure: The Spanish case. Applied Economics Letters, 12(15), 963-966.

Chou, W. L., \& Wang, Z. (2009). Regional inequality in China's health care expenditures. Health Economics, 18(S2), S137-146.

City of Osaka. (2001). Chiho Kofuzei no santei nit suite [On the calculation of the Local Allocation Tax]. http://www.city.osaka.lg.jp/zaisei/page/0000004748.html. Last accessed February 25, 2011.

Costa-Font, J. (2010). Does devolution lead to regional inequalities in welfare activity? Environment and Planning C: Government and Policy, 28(3), 435-449. 
Costa-Font, J., \& Pons-Novell, J. (2007). Public health expenditure and spatial interactions in a decentralized national health system. Health Economics, 16(3), 291-306.

Costa-Font, J., \& Rico, A. (2006). Devolution and the interregional inequalities in health and healthcare in Spain. Regional Studies, 40(8), 875-887.

Crivelli, L., Filippini, M., \& Mosca, I. (2006). Federalism and regional health care expenditures: An empirical analysis for Swiss cantons. Health Economics, 15(5), 535-541.

D’Agostino, R. B., Belanger, A. J., \& D'Agostino Jr., R. B. (1990). A suggestion for using powerful and informative tests of normality. American Statistician, 44(4), 316-321.

Di Matteo, L., \& Di Matteo, R. (1998). Evidence on the determinants of Canadian provincial government health expenditures: 1965-1991. Journal of Health Economics, 17(2), 211228.

Fang, P., Dong, S., Xiao, J., Liu, C., Feng, X., \& Wang, Y. (2010). Regional inequality in health and its determinants: Evidence from China. Health Policy, 94(1), 14-25.

France, G. (2008). The form and context of federalism: Meanings for health care financing. Journal of Health Politics, Policy and Law, 33(4), 649-705.

Gamper-Rabindran, S., Khan, S., \& Timmins, C. (2010). The impact of piped water provision on infant mortality in Brazil: A quantile panel data approach. Journal of Development Economics, 92(2), 188-200.

Gasparini, C. E., \& Ramos, F. S. (2004). Relative deficit of health services in Brazilian states and regions. Brazilian Review of Econometrics, 24(1), 75-107.

Gerdtham, U. G., \& Jönsson, B. (2000). International comparisons of health expenditure: Theory, data and econometric analysis. In A. J. Culyer \& J. P. Newhouse (Eds.), Handbook of Health Economics Volume 1 (pp. 11-53). Amsterdam: Elsevier Science B.V.

Gordon, R. L., Gerzoff, R. B., \& Richards, T. B. (1997). Determinants of US local health department expenditures, 1992 through 1993. American Journal of Public Health, 87(1), 91-95.

Häkkinen, U., \& Luoma, K. (1995). Determinants of expenditure variation in health care and care of the elderly among Finnish municipalities. Health Economics, 4(3), 199-211.

Imai, H., Hosomi, J., Nakao, H., Tsukino, H., Katoh, T., Itoh, T., \& Yoshida, T. (2005). Characteristics of psychiatric hospitals associated with length of stay in Japan. Health Policy, 74(2), 115-121.

Japan Association of City Mayors (2008). Chiho Kofuzei Seido no Jujitu wo Motomete [Toward the Consolidation of the Local Allocation Tax]. http://www.mayors.or.jp/ opinion /teigen/2004teigen.htm. Last accessed February 25, 2011.

Jiménez-Rubio, D., Smith, P. C., \& Van Doorslaer, E. (2008). Equity in health and health care in a decentralised context: Evidence from Canada. Health Economics, 17(3), 377-392.

Koenker, R., \& Hallock, K. F. (2001). Quantile regression. Journal of Economic Perspectives, 15(4), 143-156.

Konishi, S. (2009). Kisokara Manabu Chiho Zaisei [The Essentials of Local Public Finance]. Tokyo: Gakuyosya.

Leigh, A. (2008). Estimating the impact of gubernatorial partisanship on policy settings and economics outcomes: A regression discontinuity approach. European Journal of Political Economy, 24(2), 256-268.

Magnussen, J., Hagen, T. P., \& Kaarboe, O. M. (2007). Centralized or decentralized? A case study of Norwegian hospital reform. Social Science \& Medicine, 64(10), 2129-2137.

Mays, G. P., \& Smith, S. A. (2009). Geographic variation in public health spending: Correlates and consequences. Health Services Research, 44(5), 1796-1817. 
Ministry of Internal Affairs and Communication (2009). Heisei 19 Nendo Shi-Cho-Son betsu Kessan Joukyo Shirabe [Annual Report on Municipal Finances FY2007]. http://www. soumu. go.jp/iken/zaisei/h19_todohuken.html. Last accessed February 25, 2011.

Ministry of Health, Welfare and Labour (2008). Seikatsu Hogo no Genjo ni tsuite [On the current situation of Public Assistance Program]. http://www.mhlw.go.jp/shingi/ 2008/11/dl/s1104-3b.pdf. Last accessed February 25, 2011.

Ministry of Health, Welfare and Labour (2010). Kanja Chosa [Patient Survey]. http://www.estat.go.jp /SG1/estat/NewList.do?tid=000001031167. Last accessed February 25, 2011.

Montero-Granados, R., De Dios Jiménez, J., \& Martín, J. (2007). Decentralisation and convergence in health among the provinces of Spain (1980-2001). Social Science \& Medicine, 64(6), 1253-1264.

Moreira, S., \& Barros, P. P. (2010). Double health insurance coverage and health care utilization: Evidence from quantile regression. Health Economics, 19(9), 1075-1092.

Moscone, F., Knapp, M., \& Tosetti, E. (2007). Mental health expenditure in England: A spatial panel approach. Journal of Health Economics, 26(4), 842-864.

Numao, N. (2009). Jichitai no Seikatsu Hogo gyosei wo meguru genjo to kadai [The current state and issues of the Public Assistance for local governments]. Shakai Seisaku Kenkyu [Social Policy Studies], (9) 159-178.

O’Brien, R. M. (2007). A caution regarding rules of thumb for variance inflation factors. Quality \& Quantity, 41(5), 673-690.

Rahman, T. (2008). Determinants of public health expenditure: Some evidence from Indian states. Applied Economics Letters, 15(11), 853-857.

Royston, P. (1992). Comment on sg3.4 and an improved D'Agostino test. Stata Technical Bulletin, 1(3), 23-24.

Scheffler, R., \& Smith, R. B. (2006). The impact of government decentralization on county health spending for the uninsured in California. International Journal of Health Care Finance and Economics, 6(3), 237-258.

Shapiro, S. S., \& Francia, R. S. (1972). An approximate analysis of variance test for normality. Journal of the American Statistical Association, 67(337), 215-216.

Shapiro, S. S., \& Wilk, M. B. (1965). An analysis of variance test for normality (complete samples). Biometrika, 52, 591-611.

STATA Corporation (2009). STATA Base Reference Manual (Release 11). College Station: STATA Corporation.

Sutton, M., \& Lock, P. (2000). Regional differences in health care delivery: Implications for a national resource allocation formula. Health Economics, 9(6), 547-559.

Suzuki, H. (2010) Seishin shogai to hinkon [Mental illness and poverty]. Available at http://www015.upp.so-net.ne.jp/hanhinkondo/gakushukai20100826.pdf Last accessed February 25, 2011.

Wagstaff, A., \& Lindelow, M. (2007). Progressivity in the financing of decentralized government health programs: A decomposition. Health Economics, 16(11), 1271-1275.

Woojin, C., Oh, S., Suh, T., Lee, Y. M., Oh, B. H., \& Yoon, C. (2010). Determinants of length of stay for psychiatric inpatients: Analysis of a national database covering the entire Korean elderly population. Health Policy, 94(2), 120-128.

Yu, K., Lu, Z., \& Stander, J. (2003). Quantile regression: Applications and current research areas. The Statistician, 52(3), 331-350. 
Fig. 1 Shares in Public Assistance expenditures by assistance type: FY2007 Source: Ministry of Health, Labour and Welfare

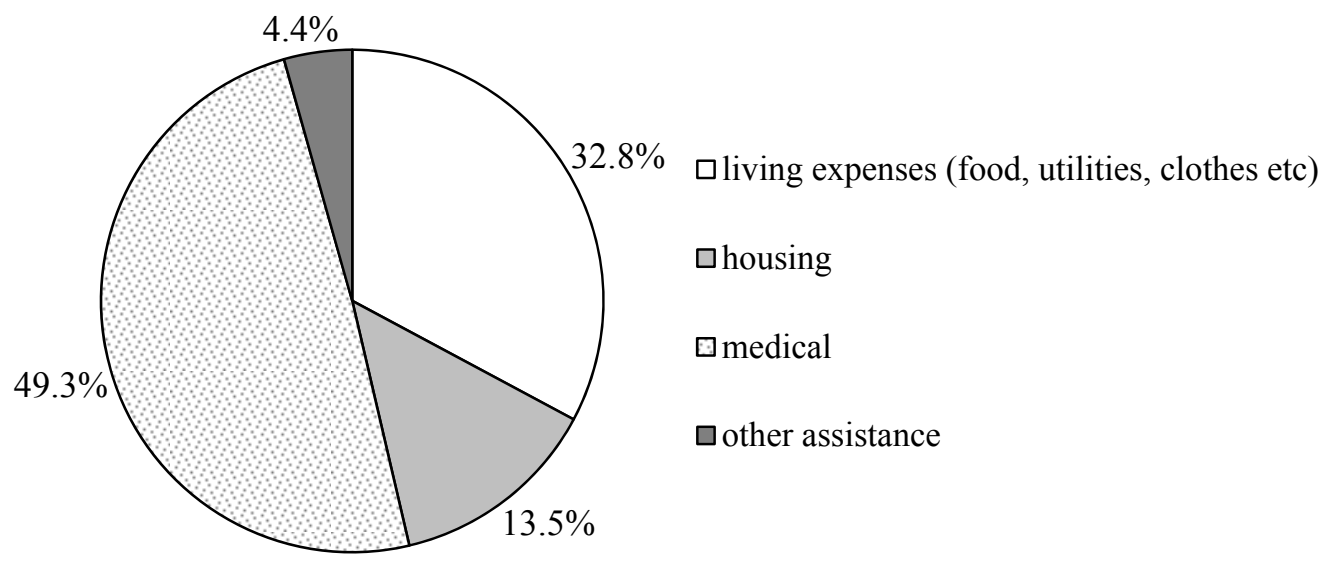

Fig. 2 Distribution of fiscal capacity index: FY2007

Source: Ministry of Internal Affairs and Communications (2009)

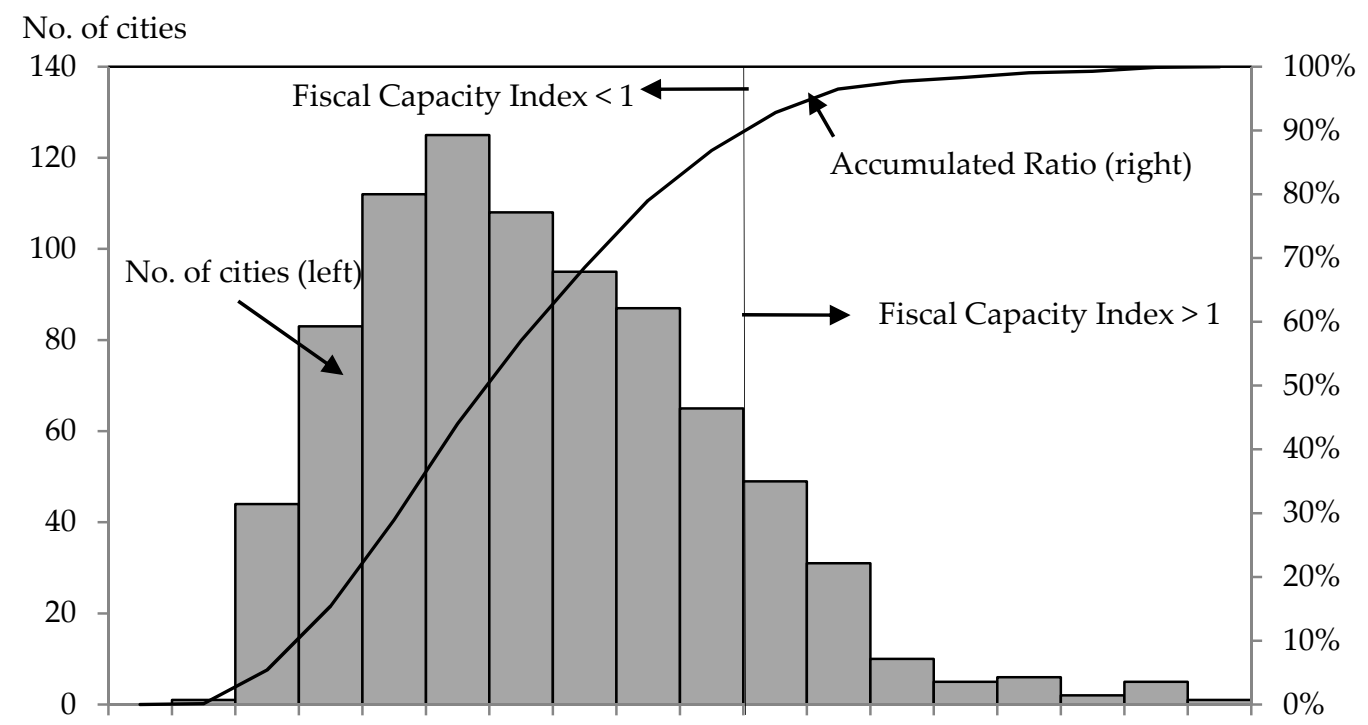

0- $0.1-0.2-0.3-0.4-0.5-0.6-0.7-0.8-0.9-1.0-1.1-1.2-1.3-1.4-1.5-1.6-1.7-$ 
Fig. 3 Distribution of transfer deficits

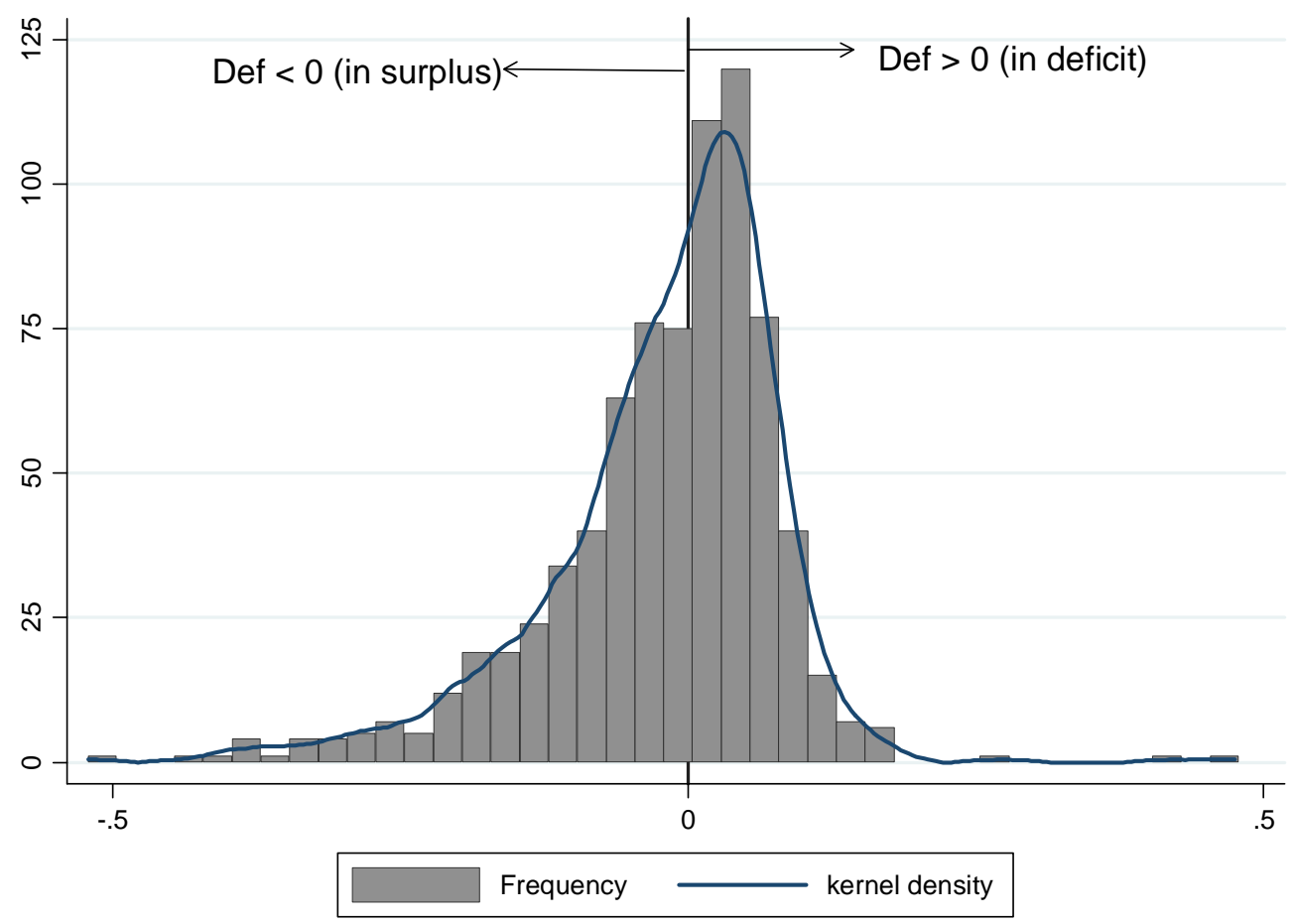

Fig. 4 Comparison of transfer deficits between 2006 and 2007

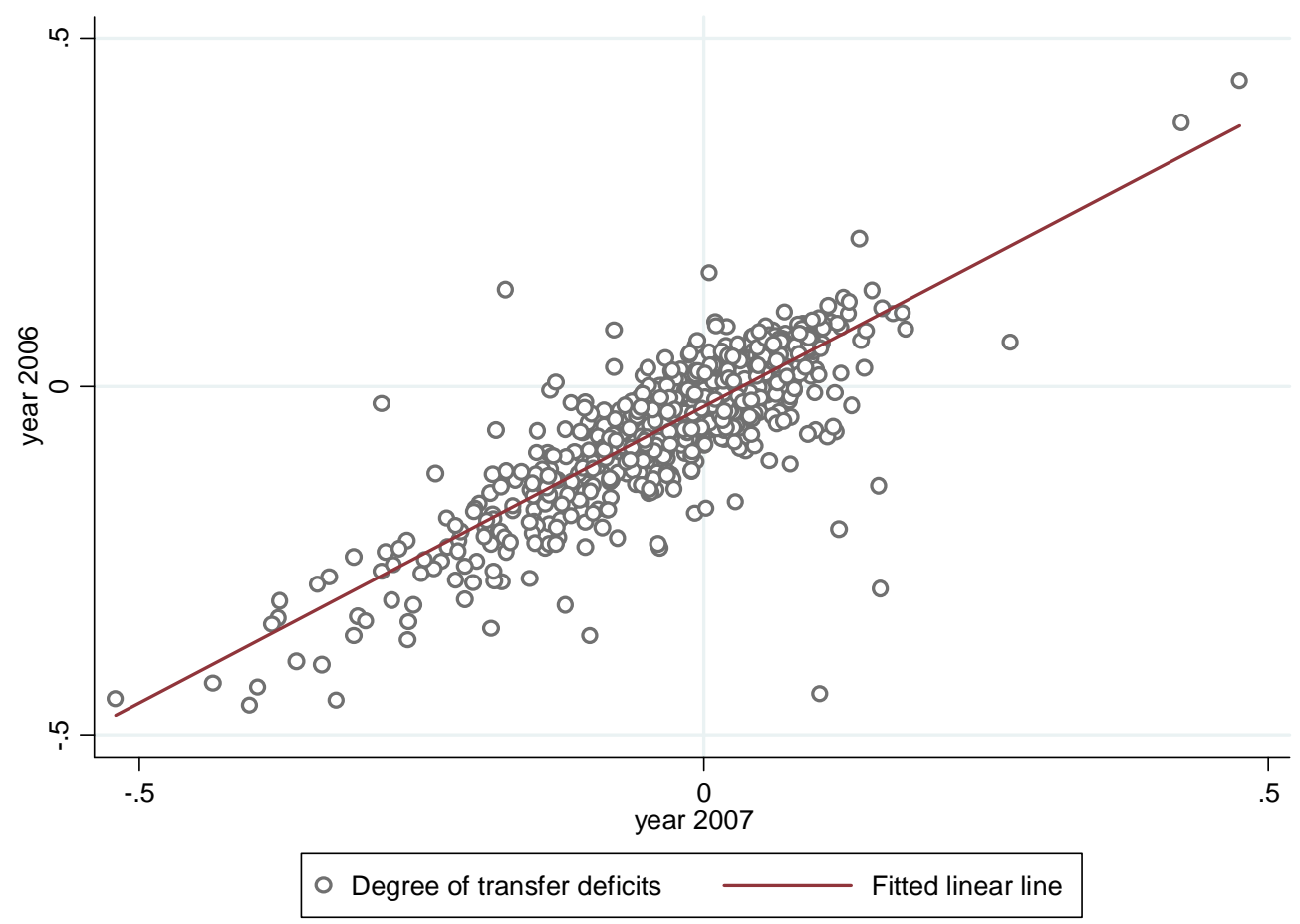


Fig. 5 Parameter estimates and confidence intervals

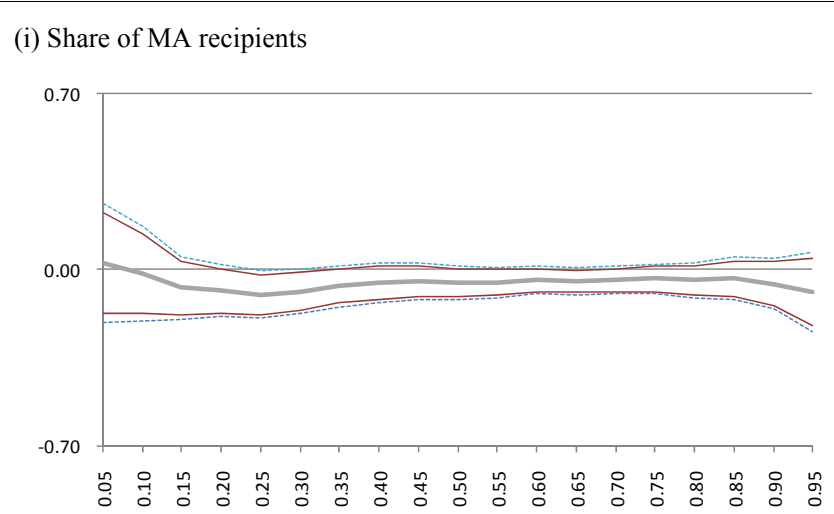

(ii) Share of MA inpatients

(iii) Share of mentally ill MA recipients

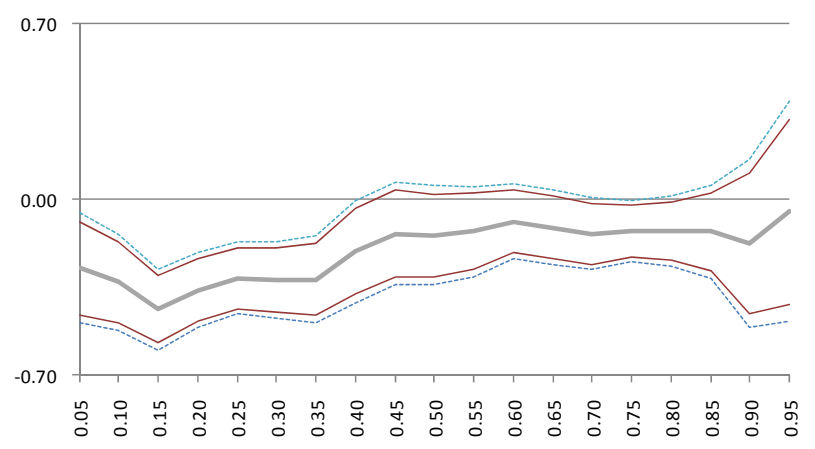

(iv) Share of mentally ill MA inpatients
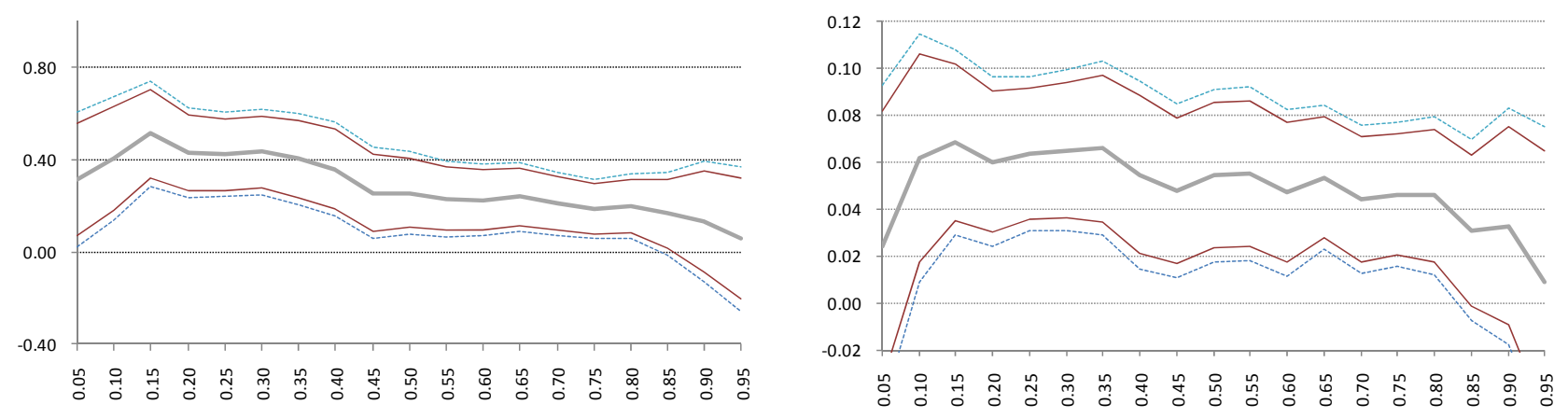

(v) Share of elderly PA households

(vi ) Share of Injured/sick PA households
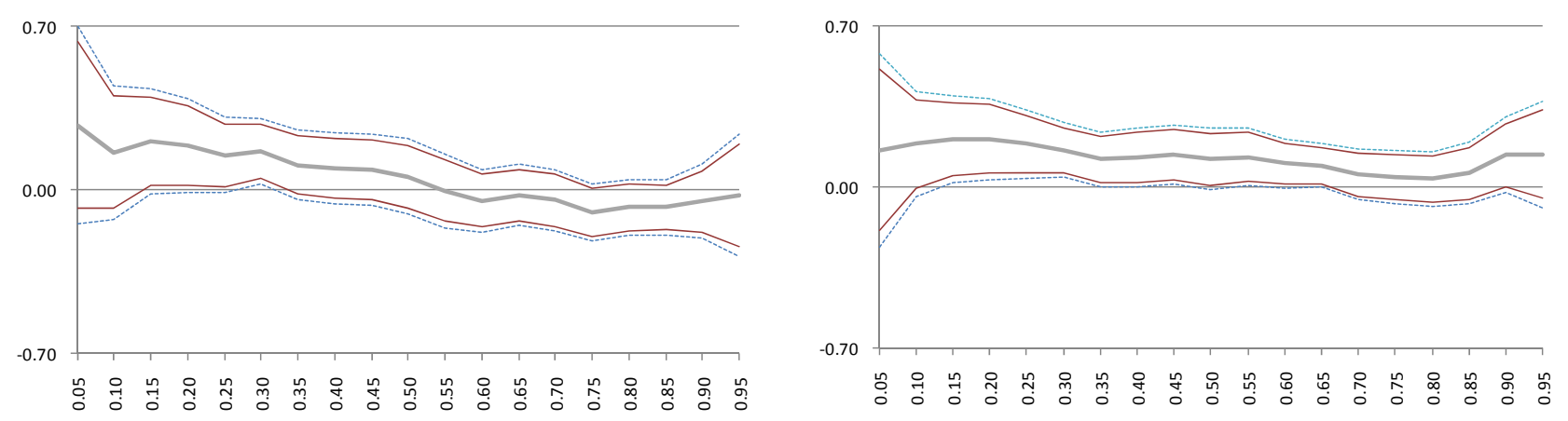

$[95 \%$

$[90 \%$

Coef.

90\%]

95\%] 
Fig. 5 Parameter estimates and confidence intervals (continued)

(vii) Share of disabled PA households

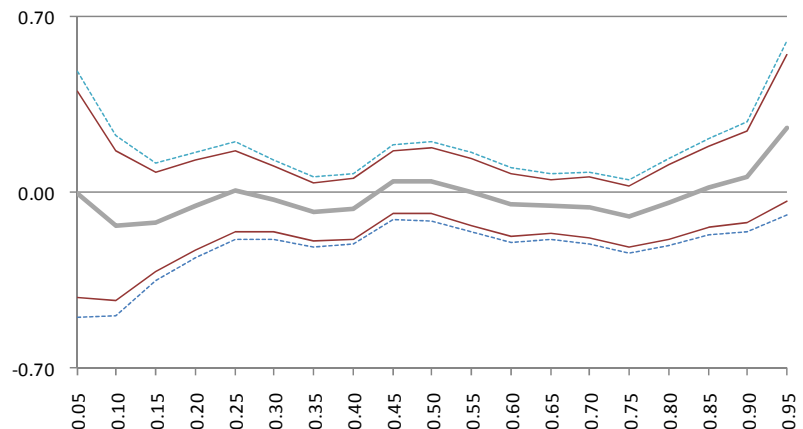

(ix) $\log$ (average \# of PA household members)

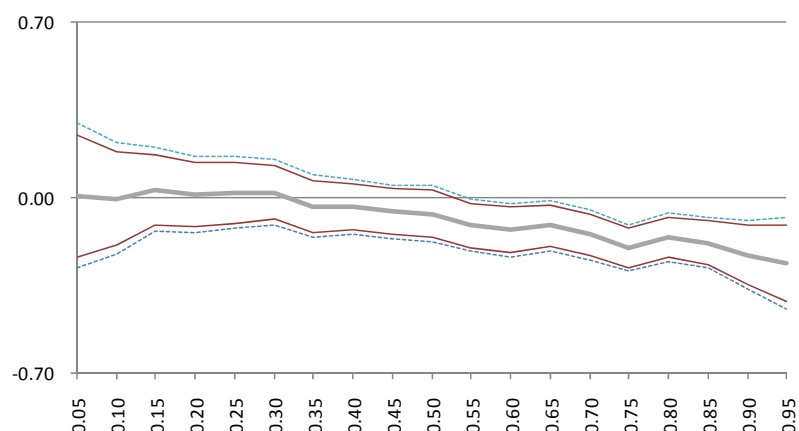

(xi) $\log ($ surface area)

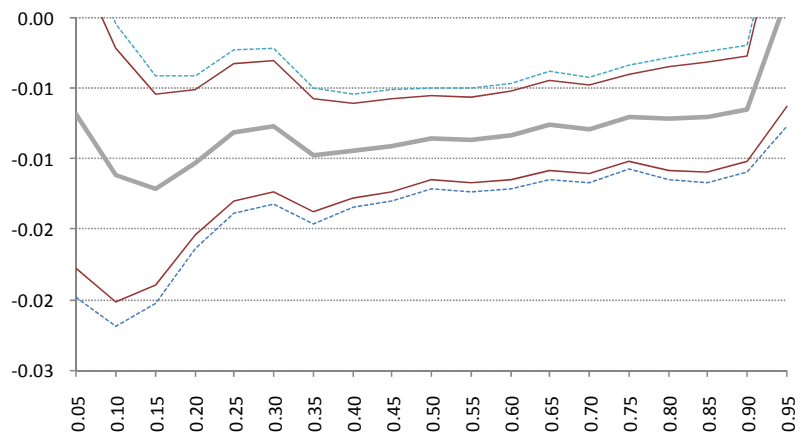

(viii) $\log$ (PA households)

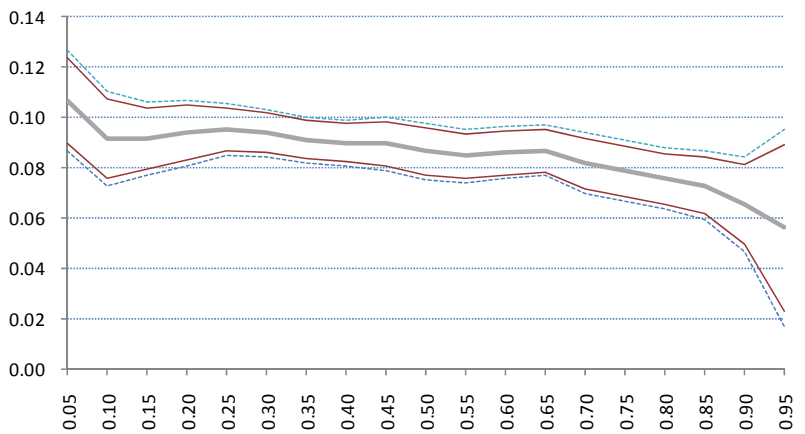

(x) $\log ($ population $)$

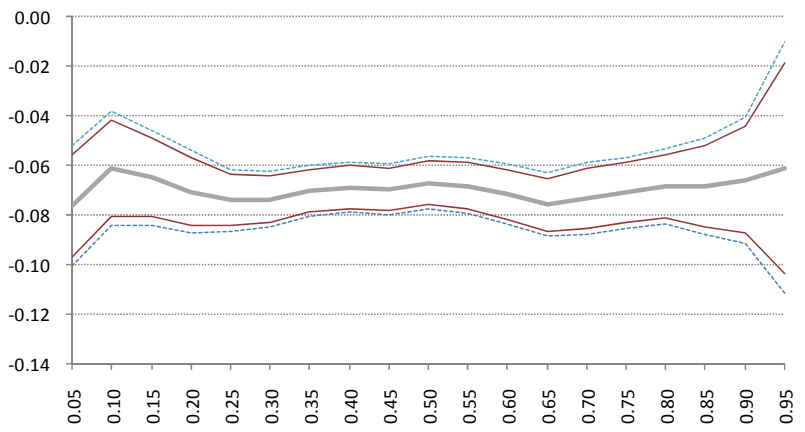

(xii) constant

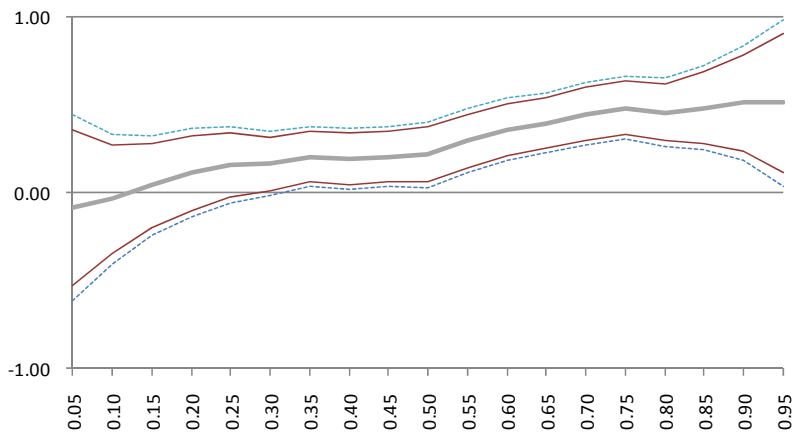

[95\% - $\left[90 \%-\frac{}{\text { Coef. }}-90 \%\right] \quad-\cdots-\cdots$ 
Table 1 Variable definitions

\begin{tabular}{|c|c|}
\hline Variables & Definitions \\
\hline Degree of transfer deficits & $\begin{array}{l}\text { Public Assistance expenditures } \div \text { (Central Government Subsidy for } \\
\text { Public Assistance }+ \text { Standard Fiscal Demand for Public Assistance })\end{array}$ \\
\hline PA households & The number of households that receive Public Assistance (PA) benefits \\
\hline PA recipients & $\begin{array}{l}\text { The number of persons (i.e., household members) that receive Public } \\
\text { Assistance (PA) benefits }\end{array}$ \\
\hline MA recipients & $\begin{array}{l}\text { The number of persons (i.e., household members) that receive Medical } \\
\text { Assistance (MA) benefits }\end{array}$ \\
\hline Share of MA recipients & The number of MA recipients $\div$ the number of PA recipients \\
\hline Share of MA inpatients & $\begin{array}{l}\text { The number inpatients that receives MA benefits } \div \text { the number of MA } \\
\text { recipients }\end{array}$ \\
\hline $\begin{array}{l}\text { Share of mentally ill MA } \\
\text { recipients }\end{array}$ & $\begin{array}{l}\text { The number of MA recipients that are mentally ill } \div \text { the number of MA } \\
\text { recipients }\end{array}$ \\
\hline $\begin{array}{l}\text { Share of mentally ill MA } \\
\text { inpatients }\end{array}$ & $\begin{array}{l}\text { The number of MA recipients that are mentally ill and hospitalized } \div \\
\text { the number of MA recipients that are mentally ill. }\end{array}$ \\
\hline $\begin{array}{l}\text { Share of elderly PA } \\
\text { households }\end{array}$ & $\begin{array}{l}\text { The number of PA households whose household members are all aged } \\
65 \text { or above } \div \text { the total number of PA households }\end{array}$ \\
\hline $\begin{array}{l}\text { Share of injured/sick PA } \\
\text { households }\end{array}$ & $\begin{array}{l}\text { The number of PA households whose heads are injured or sick } \div \text { the } \\
\text { total number of PA households }\end{array}$ \\
\hline $\begin{array}{l}\text { Share of disabled PA } \\
\text { households }\end{array}$ & $\begin{array}{l}\text { The number of PA households whose heads are disabled } \div \text { the total } \\
\text { number of PA households }\end{array}$ \\
\hline $\begin{array}{l}\text { Average PA household } \\
\text { members }\end{array}$ & The total number of PA recipients $\div$ the total number of PA households \\
\hline
\end{tabular}

Note: The data are all from unpublished municipal data provided by the Ministry of Health, Labour and Welfare for FY2007. 
Table 2 Sample statistics

\begin{tabular}{|c|c|c|c|c|c|c|c|c|c|c|c|c|}
\hline \multirow{2}{*}{ Variables } & \multirow{2}{*}{ Mean } & \multirow{2}{*}{ S.D. } & \multirow{2}{*}{ Skewness } & \multirow{2}{*}{ Kurtosis } & \multirow{2}{*}{ Min. } & \multicolumn{5}{|c|}{ Quantiles } & \multirow{2}{*}{ Max. } & \multirow{2}{*}{ VIF } \\
\hline & & & & & & $15 \%$ & $25 \%$ & $50 \%$ & $75 \%$ & $85 \%$ & & \\
\hline Degree of transfer deficits & -.020 & .101 & -.937 & 6.139 & -.521 & -.110 & -.063 & .001 & .045 & .064 & .475 & n.a. \\
\hline Share of MA recipients & .831 & .079 & -.547 & 3.232 & .519 & .750 & .780 & .838 & .892 & .917 & .994 & 1.23 \\
\hline Share of MA inpatients & .135 & .063 & 1.580 & 6.858 & .034 & .079 & .093 & .122 & .161 & .192 & .483 & 2.18 \\
\hline Share of mentally ill MA recipients & .101 & .057 & 1.327 & 5.681 & .010 & .047 & .061 & .089 & .128 & .155 & .405 & 2.21 \\
\hline Share of mentally ill MA inpatients & .729 & .230 & -.684 & 2.570 & .000 & .447 & .581 & .769 & .928 & .987 & 1.000 & 1.74 \\
\hline Share of elderly PA households & .464 & .073 & .476 & 4.175 & .176 & .392 & .415 & .458 & .505 & .538 & .764 & 3.36 \\
\hline Share of injured/sick PA households & .252 & .066 & -.038 & 3.754 & .001 & .189 & .212 & .236 & .291 & .315 & .500 & 2.15 \\
\hline Share of disabled PA households & .134 & .049 & 1.273 & 6.034 & .003 & .090 & .103 & .126 & .157 & .179 & .395 & 2.15 \\
\hline $\log (\mathrm{PA}$ households $)$ & 5.974 & 1.253 & .744 & 3.897 & 3.178 & 4.745 & 5.124 & 5.826 & 6.662 & 7.172 & 11.368 & 4.07 \\
\hline $\log$ (average PA household members) & .302 & .091 & -.021 & 2.817 & .041 & .206 & .241 & .302 & .367 & .396 & .584 & 2.76 \\
\hline $\log$ (population) & 11.299 & .873 & .938 & 4.303 & 8.501 & 10.469 & 10.686 & 11.130 & 11.748 & 12.172 & 15.092 & 3.46 \\
\hline $\log ($ surface area $)$ & 5.021 & 1.176 & -.384 & 2.538 & 1.629 & 3.732 & 4.272 & 5.140 & 5.930 & 6.305 & 7.686 & 1.13 \\
\hline
\end{tabular}


Table 3 Estimation results

\begin{tabular}{|c|c|c|c|c|c|c|c|}
\hline & \multirow{2}{*}{ OLS } & \multicolumn{5}{|c|}{ Quantile } & \multirow{2}{*}{$\begin{array}{l}\text { Constant } \\
\text { across } \\
\text { quantiles? }\end{array}$} \\
\hline & & .15 & .25 & .50 & .75 & .85 & \\
\hline $\begin{array}{l}\text { Share of MA } \\
\text { recipients }\end{array}$ & $\begin{array}{l}-.053 \\
(.046)\end{array}$ & $\begin{array}{l}-.073 \\
(.065)\end{array}$ & $\begin{array}{l}-.099^{* *} \\
(.048)\end{array}$ & $\begin{array}{l}-.051 \\
(.034)\end{array}$ & $\begin{array}{l}-.036 \\
(.030)\end{array}$ & $\begin{array}{l}-.036 \\
(.043)\end{array}$ & $\begin{array}{c}\text { Not rejected } \\
\quad[.665]\end{array}$ \\
\hline $\begin{array}{l}\text { Share of MA } \\
\text { inpatients }\end{array}$ & $\begin{array}{l}-.176^{* *} \\
(.080)\end{array}$ & $\begin{array}{c}-.436^{* * *} \\
(.082)\end{array}$ & $\begin{array}{l}-.313^{* * *} \\
(.073)\end{array}$ & $\begin{array}{l}-.142 \\
(.100)\end{array}$ & $\begin{array}{l}-.124^{* *} \\
(.062)\end{array}$ & $\begin{array}{l}-.126 \\
(.094)\end{array}$ & $\begin{array}{l}\text { Rejected }^{* *} \\
{[.016]}\end{array}$ \\
\hline $\begin{array}{l}\text { Share of mentally ill } \\
\text { MA recipients }\end{array}$ & $\begin{array}{l}.242^{* * *} \\
(.079)\end{array}$ & $\begin{array}{l}.513^{* * *} \\
(.117)\end{array}$ & $\begin{array}{l}.423^{* * *} \\
(.094)\end{array}$ & $\begin{array}{l}.256^{* * *} \\
(.091)\end{array}$ & $\begin{array}{l}.187^{* * *} \\
(.066)\end{array}$ & $\begin{array}{l}.166^{*} \\
(.092)\end{array}$ & $\begin{array}{c}\text { Rejected }^{* *} \\
{[.035]}\end{array}$ \\
\hline $\begin{array}{l}\text { Share of mentally ill } \\
\text { MA inpatients }\end{array}$ & $\begin{array}{l}.046^{* *} \\
(.018)\end{array}$ & $\begin{array}{l}.068^{* * *} \\
(.020)\end{array}$ & $\begin{array}{l}.064^{* * *} \\
(.017)\end{array}$ & $\begin{array}{l}.054^{* * *} \\
(.019)\end{array}$ & $\begin{array}{l}.046^{* * *} \\
(.016)\end{array}$ & $\begin{array}{c}.031 \\
(.020)\end{array}$ & $\begin{array}{c}\text { Not rejected } \\
\text { [.599] }\end{array}$ \\
\hline $\begin{array}{l}\text { Share of elderly PA } \\
\text { households }\end{array}$ & $\begin{array}{l}.107 \\
(.068)\end{array}$ & $\begin{array}{l}.210^{*} \\
(.114)\end{array}$ & $\begin{array}{l}.151^{*} \\
(.081)\end{array}$ & $\begin{array}{c}.060 \\
(.082)\end{array}$ & $\begin{array}{l}-.094 \\
(.063)\end{array}$ & $\begin{array}{l}-.074 \\
(.059)\end{array}$ & $\begin{array}{l}\text { Rejected }^{* *} \\
{[.035]}\end{array}$ \\
\hline $\begin{array}{l}\text { Share of injured/sick } \\
\text { PA households }\end{array}$ & $\begin{array}{l}.151^{* *} \\
(.064)\end{array}$ & $\begin{array}{l}.210^{* *} \\
(.097)\end{array}$ & $\begin{array}{l}.189^{* *} \\
(.076)\end{array}$ & $\begin{array}{l}.122^{*} \\
(.068)\end{array}$ & $\begin{array}{l}.043 \\
(.058)\end{array}$ & $\begin{array}{c}.061 \\
(.068)\end{array}$ & $\begin{array}{c}\text { Not rejected } \\
\quad[.500]\end{array}$ \\
\hline $\begin{array}{l}\text { Share of disabled PA } \\
\text { households }\end{array}$ & $\begin{array}{l}.011 \\
(.079)\end{array}$ & $\begin{array}{l}-.116 \\
(.120)\end{array}$ & $\begin{array}{c}.007 \\
(.098)\end{array}$ & $\begin{array}{c}.047 \\
(.081)\end{array}$ & $\begin{array}{l}-.095 \\
(.075)\end{array}$ & $\begin{array}{c}.023 \\
(.099) \\
\end{array}$ & $\begin{array}{c}\text { Not rejected } \\
{[.171]}\end{array}$ \\
\hline $\log$ (\# PA households) & $\begin{array}{l}.095^{* * *} \\
(.006)\end{array}$ & $\begin{array}{l}.091^{* * *} \\
(.008)\end{array}$ & $\begin{array}{l}.095^{* * *} \\
(.005)\end{array}$ & $\begin{array}{l}.086^{* * *} \\
(.006)\end{array}$ & $\begin{array}{l}.079^{* * *} \\
(.006)\end{array}$ & $\begin{array}{l}.073^{* * *} \\
(.007)\end{array}$ & $\begin{array}{l}\text { Rejected }^{* *} \\
{[.047]}\end{array}$ \\
\hline $\begin{array}{l}\log (\text { average \# PA } \\
\text { household members) }\end{array}$ & $\begin{array}{l}-.071 \\
(.050)\end{array}$ & $\begin{array}{l}.032 \\
(.085)\end{array}$ & $\begin{array}{l}.019 \\
(.073)\end{array}$ & $\begin{array}{l}-.064 \\
(.057)\end{array}$ & $\begin{array}{l}-.200^{* * *} \\
(.047)\end{array}$ & $\begin{array}{l}-.180^{* * *} \\
(.052)\end{array}$ & $\begin{array}{l}\text { Rejected }^{* *} \\
{[.012]}\end{array}$ \\
\hline $\log ($ population $)$ & $\begin{array}{c}-.076^{* * *} \\
(.007)\end{array}$ & $\begin{array}{l}-.065^{* * *} \\
(.010)\end{array}$ & $\begin{array}{c}-.074^{* * *} \\
(.006)\end{array}$ & $\begin{array}{l}-.067^{* * *} \\
(.005)\end{array}$ & $\begin{array}{l}-.071^{* * *} \\
(.007)\end{array}$ & $\begin{array}{c}-.068^{* * *} \\
(.010)\end{array}$ & $\begin{array}{c}\text { Not rejected } \\
\quad[.520]\end{array}$ \\
\hline $\log ($ surface area $)$ & $\begin{array}{l}-.008^{* * *} \\
(.002)\end{array}$ & $\begin{array}{l}-.012^{* *} \\
(.004)\end{array}$ & $\begin{array}{l}-.008^{* * *} \\
(.003)\end{array}$ & $\begin{array}{l}-.009^{* * *} \\
(.002)\end{array}$ & $\begin{array}{l}-.007^{* * *} \\
(.002)\end{array}$ & $\begin{array}{l}-.007^{* * *} \\
(.002)\end{array}$ & $\begin{array}{l}\text { Not rejected } \\
\quad[.620]\end{array}$ \\
\hline Constant & $\begin{array}{l}.257^{* *} \\
(.102)\end{array}$ & $\begin{array}{l}.043 \\
(.144)\end{array}$ & $\begin{array}{l}.163 \\
(.111)\end{array}$ & $\begin{array}{l}.219^{* *} \\
(.095)\end{array}$ & $\begin{array}{l}.485^{* * *} \\
(.091)\end{array}$ & $\begin{array}{l}.485^{* * *} \\
(.123)\end{array}$ & - \\
\hline $\begin{array}{l}\text { Adjusted } R^{2} \text { for OLS/ } \\
\text { Pseudo } R^{2} \text { for } Q R\end{array}$ & .514 & .435 & .406 & .336 & .250 & .194 & - \\
\hline
\end{tabular}

Notes: $\quad 1$. Sample size is 782 .

2. Robust standard errors are in parentheses for OLS.

3. Standard errors for quantile regressions are based on bootstrap with 100 replications.

4. Asterisks ***,**, and * indicate statistical significance at the $0.01,0.05$, and 0.10 levels, respectively.

5. Box brackets in the "constant across quantiles?" column show $P$ values for the null hypothesis that the coefficients on the relevant variable are equal at the $0.15,0.25,0.50,0.75$, and 0.85 quantiles. 


\section{Appendix}

Table A1 List of acronyms

\begin{tabular}{|c|c|}
\hline Acronyms & Definitions \\
\hline CGS & Central Government Subsidy \\
\hline CGS-PA & Central Government Subsidy for Public Assistance \\
\hline FCI & Fiscal Capacity Index \\
\hline JACM & Japan Association of City Mayors \\
\hline LAT & Local Allocation Tax \\
\hline MA & Medical Assistance \\
\hline MHLW & Ministry of Health, Labour and Welfare \\
\hline MIC & Ministry of Internal Affairs and Communication \\
\hline OLAT & Ordinary Local Allocation Tax \\
\hline PA & Public Assistance \\
\hline SFD & Standard Fiscal Demand \\
\hline SFD-PA & Standard Fiscal Demand for Public Assistance \\
\hline SFR & Standard Fiscal Revenue \\
\hline SLAT & Special Local Allocation Tax \\
\hline QR & Quantile regression \\
\hline VCME & Variance-covariance matrix estimator \\
\hline
\end{tabular}

